\title{
The Development of A Versatile Movable Barrier Solution
}

\author{
Meng $\mathrm{Li}^{1, \mathrm{a}}$ \\ ${ }^{1}$ Research Institute of Highway, Ministry of Transport, Xituchenglu8hao, Beijing, China
}

\begin{abstract}
To reduce the accident risk of work zone on highway, a new movable barrier solution is presented in this paper. The barrier is effective, affordable, environment-friendly and versatile. It can raise the level of highway safety performance in work zone, median opening and tidal lane. The development of the versatile movable barrier took reliability, mobility, economical efficiency, construction convenience into account. Researchers optimized structure by finite element analysis as well as mechanic analysis. The finite element analysis was accomplished by LS-DYNA. This barrier set eventually passed simulated impact tests, which proved that it is able to fulfil the requirement of $160 \mathrm{kj}$-level safety performance.
\end{abstract}

\section{Introductions}

Highway barrier is generally used to prevent run-off-theroad crashes, which result from vehicle running off the roadway or into opposite lanes. Run-off-the-road crashes often lead to serious casualty and property damage, and they are an important cause of secondary accidents. Many countries and research agencies have invested resources and man-power on barrier development. However, most of the efforts work on traditional barriers such as concrete barrier, w-beam barriers. Comparing with these traditional barriers, movable barrier did not gain enough attention.

With a boost of highway mileage, the demand of roadway maintenances and highway upgrade construction keeps augmenting. It causes vehicle crashes in work zone and consequently increases the risk of fatal and injury accidents. The accident shown in the Figure 1 is a crash happening on Shenhai freeway in China. There were two lanes in a traveling direction, and one lane is closed due to construction when the crash happened. The driver of a truck at the back of a construction vehicle was too late to divert or stop, The truck rear-ended the construction vehicle and then headed off to the shoulder. After hitting another vehicle, the truck finally stopped by the barrier in the opposite lane. The accident led to one casualty and 3,000,000 Chinese yuan loss.

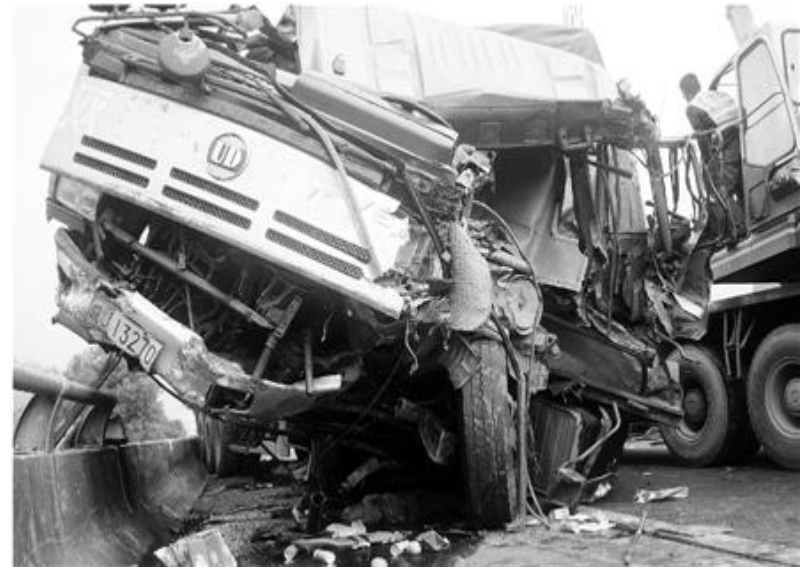

Figure 1. A work zone crash on Shenhai freeway

To avoid this kind of crashes, a new type of movable barrier, which is able to serve as a set of temporary longitudinal barrier, is required for highway management agencies and contractors. Current countermeasures for work zone risk in China are varisous traffic control device such as signs, plastic drums, lights, cones, barricades, chevron panels. These traffic devices are utilized to regulate, warn and guide drivers. The main purpose of the traffic control devices is not to offer a physical protection but to advise road users how to traverse a work-zone section in a proper manner. The new movable barrier ought to meet the requirement of protection as well as guidance and warning.

\footnotetext{
${ }^{\text {a }}$ Corresponding author: 464374092@QQ.com
} 


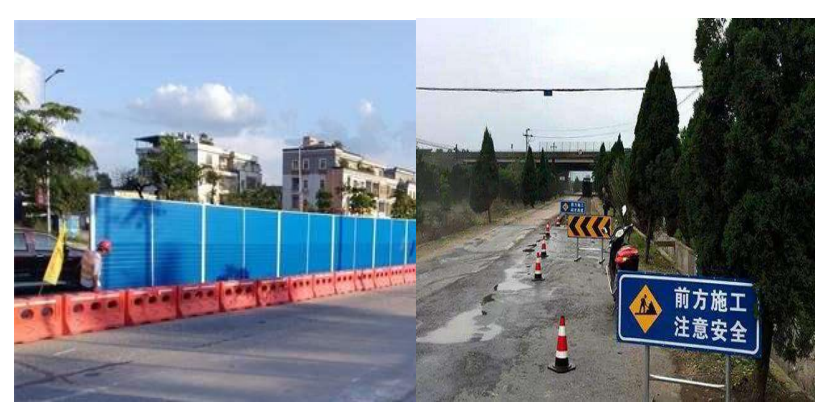

Figure 2. Traffic control devices

In addition, the new movable barriers can be widely used as temporary barrier in various locations, such as work zone, highway median opening, tidal lanes and emergency evacuation exits.

\section{Structure design}

The feasible design scheme of the movable barrier should be free-standing, movable and reliable. It can serve as a set of temporary longitudinal barriers in work zones, tidal lanes and long-term barriers in median opening. The safety performance ought to satisfy the requirement of the $160 \mathrm{kj}$-level barrier, which means the impact energy of the barrier reaches $160 \mathrm{kj}$. As a kind of the reusable facility, the new movable barrier has to guarantee mobility. Developers must limit the weight of the barrier and make them easy to be assembled. The work zone is an everchanging environment that differs in weather, humidity, location, roadway facilities and traffic flow, therefore the barrier design scheme ought to adapt to various conditions. Moreover, the new movable barrier must be feasible to different construction projects including renewal, upgrading and maintenance of infrastructure and facilities. Last but not least, the cost of the new barrier should be affordable, so it can be adopted in any region and environment. [1]

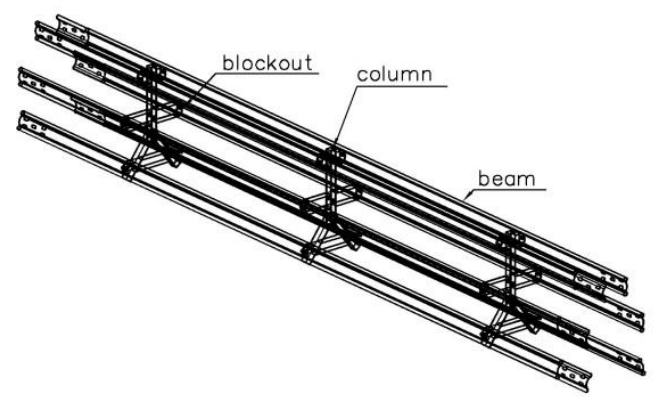

Figure 3. Standard unit

Researchers tried several different design schemes and decided the final structure design. The new barrier system consists of several standard units and two end terminals. As demonstrated in Figure 3, a standard unit is composed of three columns, six curled $\mathrm{C}$ beams, nine blockouts and bolts. The length of a standard unit is $6 \mathrm{~m}$.
By flexible combination, standard units and two end terminals are able to form a set of barriers with any length. The terminal end, shown in Figure 4, is $1.5 \mathrm{~m}$ in length, and it can be temporarily anchored in ground. The design of terminal end prevents the beam of barriers penetrating into vehicle.

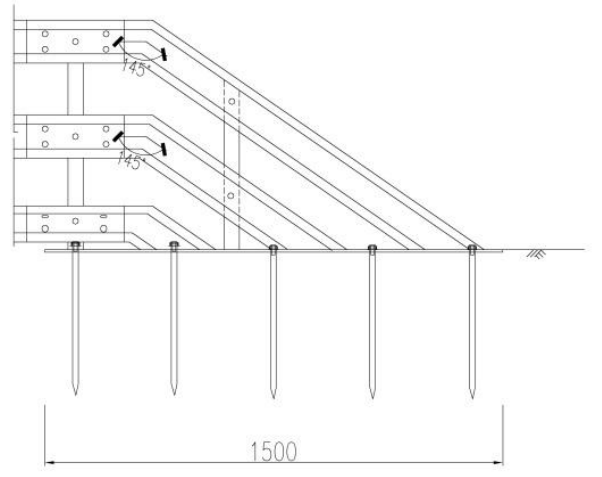

Figure 4. End terminal

The cross section of design is demonstrated in Figure 5. The barrier is $0.75 \mathrm{~m}$ in height and $0.5 \mathrm{~m}$ in width, and the unit can fit in a regular truck even a pickup. The small size makes it easy to transport and install. Installing units as a set of longitudinal barriers will only take several minutes with a few workers. Developers adopt a curled beam design scheme to offer better performance of energy absorbing and buffering. Comparing with the traditional w beam, the curled beam of the new movable barrier has not only better mechanical properties but also less weight and cost.
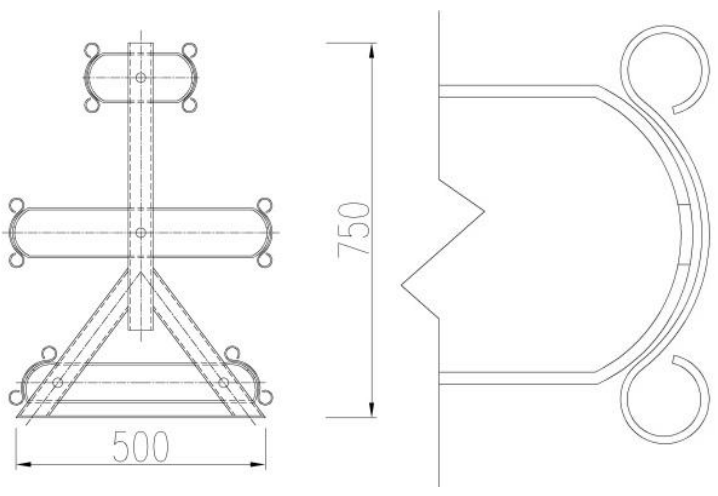

Figure 5. Cross section design

Another important design element to meet potential customer's need is the material. Researchers choose Q235 steel, which is a type of carbon steel. Q235 steel is a common steel material in Chinese market. Its yield strength reaches $235 \mathrm{MPa}$, enough to provide protection performance for barriers. Due to its moderate carbon content, good comprehensive properties, high strength, plasticity and welding properties, it has been widely used in many fields like civil engineering and mechanical engineering. Another advantage of Q235 steel is the 
lower price because it is widely required and manufactured.

\section{Simulation tests}

Researchers adopted Finite Element Analysis as a good method to test the safety performance of the new movable barrier. Finite Element Analysis simulates impact tests between vehicle and barriers instead of the full-scale impact test with real vehicles, which costs much more. The FEA method has already been proved reliable and effective. LS-DYNA, a mature finite element analysis program, is selected to accomplish simulation tests. LS-DYNA algorithm is mainly based on Lagrange equation, and the program automatically calculates the time step to satisfy the stability requirement. Test objects are meshed by four-node tetrahedral element, eight-node cubic element, two-node beam element, three-node element and four-node shell element. LS-DYNA contains a lot of material models, contact elements and collision algorithms, which enable researchers to simulate complex impact process. Figure 6 shows the meshed structure model ready for impact simulation of the new movable barrier.

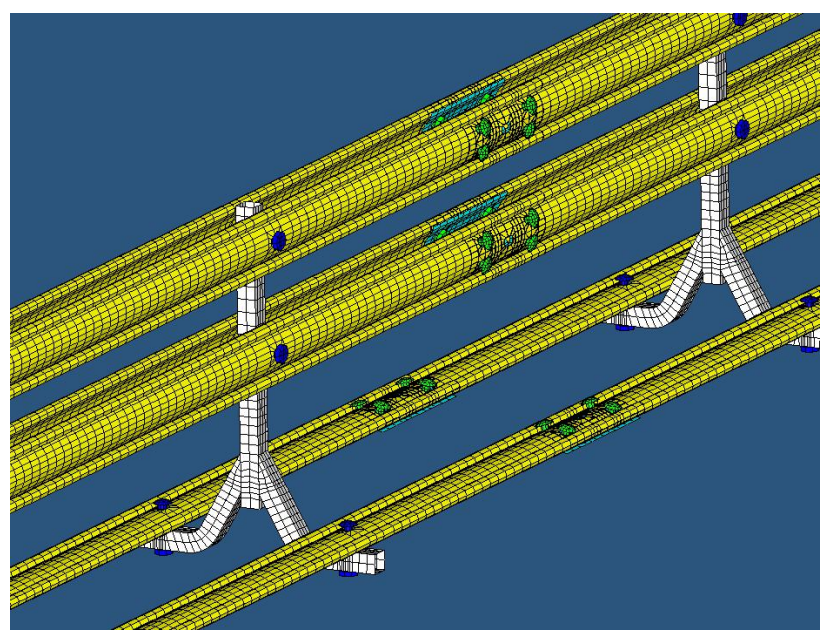

Figure 6. The meshed structure model

The impact conditions of simulation tests are set in accordance with Standard for Safety Performance Evaluation of Highway Barriers, which is the current Chinese evaluation standard of highway safety facilities. According to the standard, there are three impact tests required in the barrier evaluation, including car-barrier, truck-barrier and bus-barrier impact tests. Impact conditions are demonstrated as in Table 1. The impact angle for all of three $160 \mathrm{kj}-$ level tests is $20^{\circ}$; the vehicle mass and speed vary basing on different vehicle types. The test is similar but not exactly same with TB11,TB41,TB42 in European evaluation standard. $[2][3][4][5]$
Table 1. Impact test conditions

\begin{tabular}{|c|c|c|c|c|c|}
\hline $\begin{array}{c}\text { Test } \\
\text { No }\end{array}$ & Vehicle & $\begin{array}{c}\text { Mass } \\
\text { (ton) }\end{array}$ & $\begin{array}{c}\text { Speed } \\
(\mathrm{km} / \mathrm{h})\end{array}$ & $\begin{array}{c}\text { impact } \\
\text { angle }\end{array}$ & $\begin{array}{c}\text { Energy } \\
(\mathrm{kj})\end{array}$ \\
\hline 1 & car & 1.5 & 100 & $20^{\circ}$ & 160 \\
\hline 2 & midsize truck & 10 & 60 & $20^{\circ}$ & 160 \\
\hline 3 & midsize bus & 10 & 60 & $20^{\circ}$ & 160 \\
\hline
\end{tabular}

Figure 7 illustrates the simulation of the car-barrier test. In the FEA simulation, the test car hit the movable barrier and then was stopped by longitudinal barriers. The test vehicle was successfully contained by the movable barrier without structure failure. It did not penetrate, underride, or override the installation. The occupant velocity was $4.78 \mathrm{~m} / \mathrm{s}$ in $\mathrm{x}$ axis and $2.48 \mathrm{~m} / \mathrm{s}$ in y axis, less than $12 \mathrm{~m} / \mathrm{s}$ of requirement; the occupant acceleration was $150.32 \mathrm{~m} / \mathrm{s}^{2}$ in $\mathrm{x}$ axis and $183.62 \mathrm{~m} / \mathrm{s}^{2}$ in y axis, less than $200 \mathrm{~m} / \mathrm{s}^{2}$ of requirement.
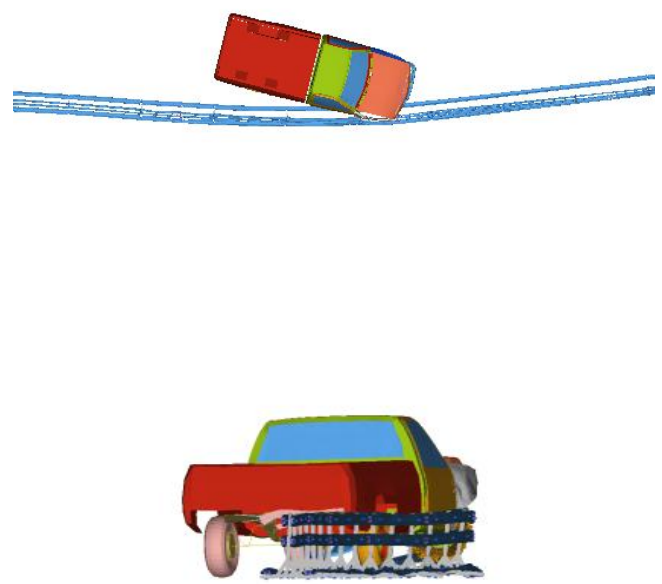

Figure 7. Car-barrier test

Figure 8 illustrates the simulation of the truck-barrier test. In the FEA simulation, the test truck first collided with the movable barrier and then got redirected back to the normal direction. There was no any structure failure such as penetrating, underriding, or overriding the installation. The test truck was successfully contained by the longitudinal barrier. 
Figure 9. Bus-barrier test
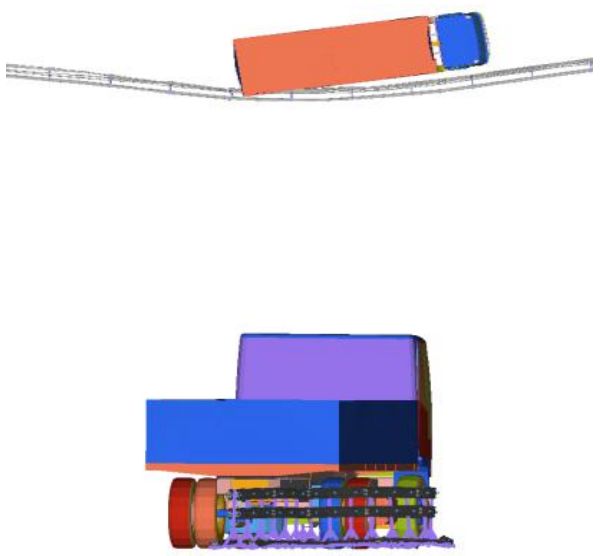

Figure 8. Truck-barrier test

Figure 9 illustrates the simulation of the bus-barrier test. In the FEA simulation, the test bus first hit the movable barrier and then got redirected back to the normal direction. There was no any structure failure such as penetrating, underriding, or overriding the installation. The test bus was contained by the longitudinal barrier, so the test was successful.
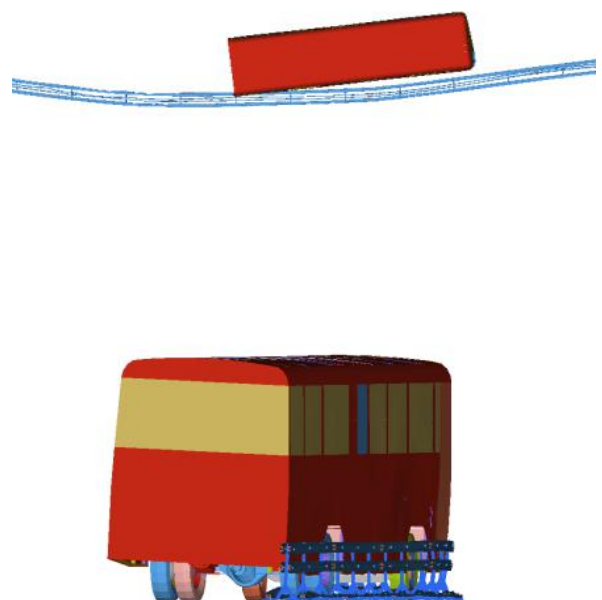

\section{Conclusion}

Based on the result of impact simulation tests, the development of the new movable barrier is successful. The steel consumption per meter is $52.8 \mathrm{~kg}$, which lowers the cost of the movable barrier to $46 \$$ per meter. The cost-benefit quality is outstanding for a movable barrier solution.

The new barrier solution has many edges in safety performance. First, the protection function is proved by the simulation of impact tests. The barrier can contain vehicles after they run the roadside. It will decrease the severity of run-off-the-road crashes, and thus save road users' life. The application of the movable barrier will greatly raise the safety performance of highway.

Second, the average weight of the barrier is $52.8 \mathrm{~kg} / \mathrm{m}$, which will allow the barrier to be carried by most of trucks; and therefore the movable barrier has remarkable mobility.

Third, the modular structure makes it convenient to manufacture. The requirement of manufacturing process is simple. Both of these two factors keep the cost of barriers affordable. It means this solution can be implemented in many developing countries. Moreover, the movable barrier is reusable; consequently, it becomes very financially efficient.

Last but not least, the movable barrier is multifunctional. It can be used in various locations other than work zone. For example, a set of movable barriers can be employed in the median opening. It is an effective way to prevent vehicles rushing into opposite traffic flow. It can also be used in the tidal lanes to temporarily separate traveling direction.

The research offers a possible option for those who need barriers that can be quickly installed. There are numerous factors influencing the user's final choice, such as the price of material, the construction capacity, temperature, humidity, traffic volume and so on. The movable barrier discussed in this paper can fulfill most of these demands. Further research will be started to raise the safety performance grade from $160 \mathrm{kj}$-level to $280 \mathrm{kj}$ level.

\section{Acknowledgments}

The work was supported by Basic Scientific Research Project of Research Institute of Highway, Ministry of Transport (2017-9018).

\section{Reference}

1. Highway Series Editorial Board, Highway Traffic Engineering and Roadside Facilities (China Communications Press, Beijing,1999) 
2. Beijing shenhuada traffic engineering detection Co Ltd, JTG B05-01-2013 Standard for Safety Performance Evaluation of Highway Barriers (Ministry of Transport of the People's Republic of China, Beijing, 2013)

3. The Road of Scientific Research Institute of the Ministry of transport, JTG D81-2006 Specification for Design of Highway Safety Facilities (Ministry of Transport of the People's Republic of China, Beijing, 2006)
4. American Association of State Highway and Transportation Officials Executive Committee, Manual for Assessing Safety Hardware 2009 (AASHTO, Washington DC, 2009)

5. CEN, EN 1317:1998. Road restraint systems (CEN, Brussels, 1998) 